\title{
LA LEY ARGELINA SOBRE VIOLENCIA CONTRA LAS MUJERES: CONTEXTUALIZACIÓN, VALORACIÓN Y TRADUCCIÓN AL ESPAÑOL
}

\author{
Carmelo PÉREZ BeLtRÁN \\ Área de Estudios Árabes e Islámicos. \\ Departamento de Estudios Semíticos \\ Facultad de Filosofía y Letras. \\ Universidad de Granada \\ carmelop@ugr.es
}

\section{INTRODUCCIÓN}

El 30 de diciembre del año 2015 fue publicada en el Boletín Ofcial del Estado la Ley núm. 15/19 modificando y completando el Código Penal argelino, que ha sido denominada por los actores sociopolíticos y los medios de comunicación como la «Ley sobre la violencia contra las mujeres» (Qānūn al-inf didd al-mar'a). Se trata de una Ley, durante mucho tiempo reivindicada por diversos movimientos de la sociedad civil argelina, principalmente asociaciones de mujeres y de derechos humanos, que pretende dar respuesta a una dura realidad que afecta directamente a las mujeres «por el hecho mismo de serlo» ${ }^{1}$, como se ha dejado patente en algunos documentos internacionales de lucha contra este tipo de violencia.

Será objeto de este estudio ${ }^{2}$ analizar el contenido de la Ley núm. 15/19 y, para su mejor comprensión, perfilar el contexto y los debates sobre la violencia contra las mujeres en Argelia durante las últimas décadas. Finalmente se aportará la traducción al español de dicha Ley a partir de

1 Así definido en la Exposición de Motivos de Ley Orgánica 1/2004, de 28 de diciembre, de Medidas de Protección Integral contra la Violencia de Género (BOE, núm. 313, de 29 de diciembre de 2004).

${ }^{2}$ Este trabajo se enmarca dentro del proyecto de investigación «Ideología, texto y discurso: las narrativas del cambio social en el Norte de África» (FFI 2016-76307-R), subvencionado por la Dirección General de Investigación Científica y Técnica. Investigador principal: Juan Antonio Macías Amoretti. 
la versión original en árabe que aparece en el Boletín Oficial del Estado

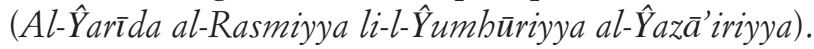

\section{Violencia contra las mujeres/violencia de género en Argelia: el debate sobre la terminología}

Lo primero que hay que señalar es que la denominación «violencia contra las mujeres» no aparece como tal en la Ley publicada en el Boletín Ofcial, cuyo texto exacto es el siguiente: «Ley núm. 15/19, del 18 de rabì al-awwal del año 1437, correspondiente al 30 de diciembre de 2015, modificando y completando la Orden núm. 66/156, del 18 de șafar de 1386, correspondiente al 8 de junio de 1966, que contiene el Código Penal». Se trata, por tanto, de una norma que modifica y completa el Código Penal

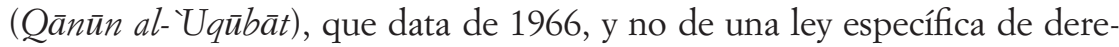
chos fundamentales para luchar contra la violación de los derechos humanos más elementales de las mujeres. Pero, a pesar de ello, lo cierto es que la denominación «violencia contra las mujeres» sí que se encuentra presente de forma reiterativa en el discurso generado por la sociedad civil, los actores políticos y los medios de comunicación, aunque existen algunas diferencias significativas dependiendo de la fuente de donde se extraiga la información. De esta forma, en la mayor parte de la documentación en lengua francesa que trata sobre la adopción de esta norma, el término generalizado es el de «Loi sur la violence faite aux femmes», que podríamos traducir al español como «Ley sobre violencia contra las mujeres». Sin embargo, en la documentación en lengua árabe existe una diversidad mayor de denominaciones, como: Q Q̄nūn taŷrīm al-unf didd al-mar'a (Ley de criminalización de la violencia contra la mujer); Qānūn mukāfah al-unf didd al-mar'a (Ley de lucha contra la violencia contra la mujer); Qānūn li-inhā' al-unf didd almar'a (Ley para erradicar la violencia contra la mujer) o la más simplificada Qānūn al- unf didd al-mar'a (Ley de violencia contra la mujer). A pesar de las diferencias gramaticales en cuanto al número ${ }^{3}$ (plural en la documenta-

\footnotetext{
$3 \mathrm{Al}$ menos desde los años ochenta del siglo xx la teoría feminista había incidido en el carácter monolítico, ficticio y abstracto del término «mujer» (en singular), que se definía esencialmente frente al concepto «hombre». Sin embargo, el término en plural (mujeres), que surge muy relacionado con el desarrollo de los feminismos periféricos (raza, clase, identidad, colonialidad, fronteras...), hace referencia a los sujetos históricos, a la diversidad de realidades y a la heterogeneidad de experiencias y vivencias entre las propias mujeres. Sobre este tema existe una amplia bibliografía. Vid., entre otros, C. Amorós y A. DE Miguel (eds.), Teoría feminista. De la ilustración a la globalización. Madrid, Minerva, 2005; M. BADRAN,
} 
ción francesa y singular en la documentación árabe) y a los matices terminológicos en árabe (criminalización, lucha, erradicar), la expresión empleada en ambas lenguas es similar: «violencia contra la/s mujer/es», cuyo referente ideológico más inmediato es la Declaración sobre la Eliminación de la Violencia contra la Mujer (DEVM), aprobada por la Asamblea General de las Naciones Unidas el 20 de diciembre de 1993. En dicha declaración se define, en su artículo primero, el concepto de «violencia contra la mujer» (la Declaración emplea el singular) como «todo acto de violencia basado en la pertenencia al sexo femenino que tenga o pueda tener como resultado un daño o sufrimiento físico, sexual o psicológico para la mujer, así como las amenazas de tales actos, la coacción o la privación arbitraria de la libertad, tanto si se producen en la vida pública como en la vida privada» ${ }^{4}$. Por su parte, el artículo segundo define las principales formas o manifestaciones de la violencia contra las mujeres, que clasifica en tres ámbitos: a) la violencia física, sexual y psicológica que se produzca en el ámbito familiar (malos tratos, abuso sexual de las niñas, violación por el marido, mutilación genital femenina explotación, etc.); b) la violencia física, sexual y psicológica perpetrada en el ámbito público (violación, abuso sexual, acoso e intimidación en el trabajo, en instituciones educacionales y en otros lugares, trata de mujeres, prostitución forzada); c) la violencia física, sexual y psicológica institucional (perpetrada o tolerada por el Estado).

A partir de los años noventa ${ }^{5}$ del siglo xx, el término «violencia contra las mujeres» convive o, más bien, compite con el de «violencia de género», cuyo uso se empieza a extender y estandarizar no sólo entre las/los teóricas/os de diferentes ámbitos de conocimiento, sino también por parte de las instituciones y organismos oficiales que terminan adoptándolo, entre ellos, el propio gobierno español a través de la Ley Orgánica 1/2004, de 28 de diciembre, de Medidas de Protección Integral contra la Violencia de Género. Esto, sin embargo, provoca no pocos debates epistemológicos. En

Feminismo en el Islam, Madrid, Cátedra, 2012; J. ButLeR, Gender Trouble. Feminism and the Subversion of Identity, New York, Routledge, 1990, y B. Hooks et al., Otras inapropiables: feminismos desde las fronteras, Madrid, Traficantes de Sueños, 2004.

${ }^{4}$ Esta Declaración esta disponible en http://www.ohchr.org/Sp/ProfessionalInterest/ Pages/ViolenceAgainstWomen.aspx (consultado el 18 de mayo de 2017).

5 En este sentido, la Declaración Final y la Plataforma de Acción que fueron adoptadas durante la IV Conferencia Mundial sobre las Mujeres, celebrada en Beijing entre el 4 y el 15 de septiembre de 1995, pueden ser consideradas como un hito para la opción definitiva por el término «violencia de género», ya que el género es el armazón conceptual que articula ambos documentos y en numerosas ocasiones se pone en estrecha relación con el de violencia. Vid. ambos documentos en http://www.un.org/womenwatch/daw/beijing/pdf/ $B D P f a \% 20 s . p d f$ (consultado el 18 de mayo de 2017). 
este sentido se pronuncia María Luisa Maqueda Abreu (2006) cuando afirma que la denominación «violencia contra las mujeres» que aparece en la DEVM y en otros muchos documentos de diversa naturaleza (leyes, resoluciones, estudios, medios de comunicación...) frecuentemente es ambigua e inadecuada, ya que incide más en la cuestión biológica que en la clave cultural o en la construcción social que el género implica. En palabras de la autora, «es una manifestación más de la resistencia que existe a reconocer que la violencia contra las mujeres no es una cuestión biológica, sino de género. Se trata de una variable teórica esencial para comprender que no es la diferencia entre los sexos la razón del antagonismo [...], sino que es consecuencia de una situación de discriminación intemporal que tiene su origen en una estructura social de naturaleza patriarcal» ${ }^{6}$. Dentro de este paradigma, la «violencia de género» debe ser considerada independientemente de las formas que adquiera, así como del espacio o el ámbito en el que se produzca y, en todo caso, no debe ser identificada exclusivamente con la violencia doméstica, conyugal o de pareja, como es usual, ya que «la violencia de género es un concepto complejo que abarca multitud de situaciones externas a lo afectivo, en las que subyace idéntico trasfondo de sometimiento de la mujer a la voluntad del hombre» ${ }^{7}$. La confusión entre violencia de género y violencia doméstica «contribuye a perpetuar la probada resistencia social a reconocer que el maltrato a las mujeres no es circunstancial ni neutral, sino instrumental y útil en aras a mantener un determinado orden de valores estructuralmente discriminatorio para las mujeres» ${ }^{8}$. Como afirma Antonio J. Yugueros", la violencia de género resalta la cuestión cultural de su etiología y, como tal, no está relacionada con el espacio, sino con las personas a las que va dirigida, las mujeres.

Sin embrago, el término «violencia de género» genera debate y cuenta también con sus detractoras/es ${ }^{10}$ más o menos declaradas/s, quienes no solamente le achacan una excesiva influencia de la lengua inglesa

${ }^{6}$ M. L. Maqueda, «La violencia de género. Entre el concepto jurídico y la realidad social», Revista Electrónica de Ciencia Penal y Criminología, núm. 8 (2006), disponible en bttp://criminet.ugr.es/recpc/08/recpc08-02.pdf (consultado el 18 de mayo de 2017).

7 M. MARTín SÁnCHEZ, «El género en la "violencia afectiva": clave para un examen de constitucionalidad», Estudios Constitucionales, vol. 13, núm. 1 (2015), p. 210.

${ }^{8}$ M. L. MAQUEDA, «La violencia de género...», op. cit.

9 A. J. Yugueros García, «La violencia contra las mujeres: conceptos y causas», Baratalia. Revista Castellano-Manchega de Ciencias Sociales, vol. 18 (2014), p. 149.

${ }_{10} \mathrm{Vid}$. especialmente la revisión que hace M. DE LuJÁn PIATTI en su tesis doctoral titulada Violencia contra las mujeres y alguien más... Valencia, Universidad de Valencia, 2013, pp. 26-36. 
(gender based violence/gender violence), sino que consideran que su utilización sistemática por políticos, instituciones oficiales y demás agentes sociales puede llegar a convertir el término en un eufemismo que enmascara una realidad demasiado dura de aceptar. En este sentido incide Silvia Tubert al considerar que existe un uso abusivo del término «género» que puede llegar a encubrir «las relaciones de poder entre los sexos, como sucede cuando se habla de violencia de género en lugar de violencia de los hombres hacia las mujeres: una categoría neutra que oculta la dominación masculina» ${ }^{11}$.

En esta misma línea, el Instituto Vasco de la Mujer en su informe Violencia contra las mujeres de 2009, tras señalar la diversidad de términos utilizados para definir una misma realidad, opta por la utilización del término «violencia contra las mujeres», alegando los siguientes motivos: «En primer lugar, es un término claro e inteligible para cualquier persona no experta en la materia; en segundo lugar, hace visible que son las mujeres quienes sufren este tipo de violencia, y, en tercer lugar, es la expresión que en estos momentos concita un mayor consenso social y político, y que se viene utilizando en los instrumentos jurídicos internacionales ${ }^{12}$.

En resumen, y sin ánimo de entrar en un debate exhaustivo, que no es objeto del presente estudio, podemos afirmar dos cuestiones de partida: en primer lugar, que «violencia de género» y «violencia contra las mujeres» son conceptos interconectados, como bien señala la Recomendación del Comité de Ministros del Consejo de Europa del 2002 cuando señala que «el término violencia contra la mujer ha de entenderse como cualquier acto violento por razón del género» ${ }^{13}$. En segundo lugar, que ambos conceptos se utilizan muy frecuentemente de forma sinónima, porque hacen referencia a una misma realidad, especialmente en el ámbito legislativo ${ }^{14}$. En nuestro caso, como el objeto de estudio es una norma legal y puesto que la documentación utilizada insiste en ello, optaremos por el término «vio-

${ }^{11}$ S. TUberT, «La crisis del concepto de género», en S. Tubert (ed.), Del sexo al género. Los equívocos de un concepto, Madrid, Cátedra-Universitat de València-Instituto de la Mujer, 2003, p. 8. p. 2.

${ }^{12}$ Emakunde, Instituto Vasco de la Mujer, Violencia contra las mujeres, marzo de 2009,

13 «Protección de las mujeres contra la violencia», Recomendación rec. (2002) 5 adoptada por el Comité de Ministros del Consejo de Europa el 30 de abril de 2002 y Memorándum explicativo, Apéndice a la Recomendación rec. (2002), punto 1, p. 6, disponible en bttp:// www.violenciagenero.msssi.gob.es/va/marcoInternacional/ambitoInternacional/ConsejoEuropa/Normativaldocs/Rec_2002_5_Spanish.pdf (consultado el 19 de mayo de 2017).

14 A.J. Yugueros García, «La violencia contra las mujeres...», op. cit., p. 148. 
lencia contra las mujeres», sin por ello perder la perspectiva de construcción política y cultural basada en relaciones de poder y de conflicto, que es consustancial del género.

\section{LA VIOLENCIA CONTRA LAS MUJERES EN ARGELIA: UNA APROXIMACIÓN AL CONTEXTO}

El debate sobre la violencia contras las mujeres en Argelia está directamente relacionado con dos cuestiones fundamentales: en primer lugar, con el proceso de liberalización política ${ }^{15}$ que se puso en marcha en los años ochenta del siglo xx bajo la presidencia de Šadlī Benŷedīd, cuyo signo más distintivo fue la adopción en 1989 de una nueva Constitución ${ }^{16}$ que suprimía toda referencia al socialismo, establecía la separación de poderes, quitaba protagonismo político al ejército y abría las puertas al pluripartidismo ${ }^{17}$, poniendo así punto final a veintisiete años de sistema presidencialista de partido único dominado por el histórico Frente de Liberación Nacional (FLN), el partido nacionalista que llevó al país a la independencia en 1962. Proceso éste que, a su vez, estuvo marcado por una importante crisis del modelo rentista basado en la explotación de los hidrocarburos, que hasta ese momento había caracterizado a la economía del país. Como respuesta a la crisis se pondrá en marcha un Plan de Ajuste Estructural (1986-1991), cuya consecuencia más importante será el «desmantelamiento del sector público productivo y el paso de los hidrocarburos a manos de las multinacionales» ${ }^{18}$. La grave crisis económica, unida a las precarias condiciones de vida de la población, desembocarán en las

15 Sobre este proceso político vid. principalmente la tesis doctoral de R. Bustos, El cambio político en Argelia (1988-1992). Análisis sistémico de una transición discordante, Madrid, Universidad Complutense, 2003, y J. MonTABEs, Las otras elecciones. Los procesos y sistemas electorales en el Magreb, Madrid, Agencia Española de Cooperación Internacional, 1999, pp. 195-254.

16 Vid. D. BeKE, «La Constitution algérienne de 1989: une passerelle entre le socialisme et l'islamisme?», Afrika Focus, vol. 7, núm. 3 (1991), pp. 241-272; O. BENDOURou, «La nouvelle Constitution algérienne du 28 février 1989», Revue de Droit Publique, vol. 5 (1989), pp. 1305-1328, y G. MARTín MuÑOZ, «La nueva Constitución argelina: hacia la III República», Revista de Estudios Politicos, vol. 67 (1990), pp. 261-296.

17 Sobre la evolución del sistema multipartidista en Argelia y la legislación asociada a ella vid. C. Pérez Beltrán, «Pluralismo bajo control: evolución de la Ley de Partidos Políticos en Argelia», Estudios de Asia y África, vol. 52, núm. 163 (2017), pp. 31-60.

18 A. Mañé Estrada, «Ajuste estructural en Argelia. Un diagnóstico equivocado para una difícil reforma», Nación Árabe, vol. 36 (1998), p. 96. 
trascendentales revueltas sociales, en octubre de 1988, duramente reprimidas por el ejército y las fuerzas de seguridad del Estado que, sin embargo, serán el verdadero detonante del cambio político y la expresión de una nueva movilidad social.

La segunda cuestión apuntada anteriormente es el desarrollo del movimiento de mujeres que se produce durante esta misma época, gracias también a la adopción de nuevas leyes de asociación más permisivas ${ }^{19}$ que posibilitaron la aceleración del tejido asociativo desde la legalidad, de tal manera que si en los años setenta el país contaba con 2.185 asociaciones $^{20}$ (más de la mitad, asociaciones de padres de alumnos o deportivas), esta cifra aumentó hasta 11.000 en 1988. El desarrollo de un amplio abanico de asociaciones, colectivos, grupos, talleres, aulas, seminarios, etc., de ideología muy diversa, permitió enriquecer considerablemente el debate y la lucha a favor de los derechos humanos de las mujeres, puesto que hasta ese momento la única asociación legalmente permitida, la Unión Nacional de Mujeres Argelinas ${ }^{21}$, en tanto que organización de masas del aparato ideológico del FLN, apenas sí pudo desempeñar cierta función en el ámbito educativo o de la salud.

Durante esta etapa inicial, las principales acciones del movimiento asociativo de mujeres ${ }^{22}$ tuvieron por objetivo principal la lucha contra la violencia jurídica e institucional, es decir, contra el marco jurídico que discriminaba a las mujeres, las normas que las supeditaba al hombre mediante diferentes mecanismos y cualquier otro tipo de discriminación, perpetrada o tolerada por el Estado a través de sus instituciones, que legitime la desigualdad de oportunidades y de derechos entre la ciudadanía. En este sentido, el verdadero caballo de batalla fue el Código de la familia (Qānūn

19 Entre ellas, Ley 15/87, del 21 de julio de 1987, y Decreto de aplicación 16/88, del 2 de febrero de 1988. Vid. C. PÉREZ BeLTRÁN, «Reformas jurídicas en Argelia tras la primavera árabe: la nueva ley de asociación de 2012», Anaquel de Estudios Árabes, vol. 25 (2014), pp. 181-184, y L. THIEUX, «Le secteur associatif en Algérie: la difficile émergence d'un espace de contestation politique». L'Année du Maghreb, vol. 5 (2009), pp. 129-144.

${ }^{20}$ Cifras tomadas de R. BABADJI, «L'État, les individus et les groupes en Algérie: continuité et rupture». Annuaire de l'Afrique du Nord, vol. 26 (1987), pp. 107-108.

${ }^{21}$ Vid. C. Pérez Beltrán, «La Unión Nacional de Mujeres Argelinas: organización femenina de masas», Al-Andalus Magreb, vol. 5 (1997), pp. 295-317.

${ }^{22}$ Las asociaciones más reivindicativas de los años ochenta-noventa del siglo xx eran: Asociación para la Igualdad ante la Ley entre las Mujeres y los Hombres, Asociación para la Emancipación de la Mujer, Asociación Independiente para el Triunfo de los Derechos de las Mujeres, Thighri N'tmatouth, Asociación para la Promoción de la Mujer, Coordinadora Nacional de las Asociaciones de Mujeres, etc. Vid. C. Pérez Beltrán, «Evolución del movimiento femenino y feminista en Argelia: las mujeres y la política», Estudios de Asia y África, vol. 105, núm. 33, (1998), pp. 75-102. 
al-usra), promulgado el 9 de junio de 1984, puesto que institucionalizaba jurídicamente lo que hasta ese momento era una práctica social: la discriminación de las mujeres y su subordinación al hombre. De este modo, el Código ${ }^{23}$ legalizaba la obediencia de la esposa a su marido (art. 39.1), permitía la poligamia del esposo (art. 8), exigía la presencia de un tutor para concluir el matrimonio de la esposa (art. 31), prohibía exclusivamente a las mujeres contraer matrimonio con cualquier hombre no musulmán (art. 31), establecía la obligatoriedad de mantener a la esposa (art. 37), dificultaba el divorcio a petición de la mujer y por consentimiento mutuo (arts. 53-54), discriminaba a las mujeres en la herencia, arrebataba a las madres la tutela de sus hijos (art. 87), entre un largo etcétera que no podemos explicar en este estudio aproximativo. Junto a esta norma, que fue finalmente modificada en $2005^{24}$, otros ámbitos de lucha, como la secularización de las estructuras sociales, la eliminación del analfabetismo femenino, la extensión de la educación y la mayor presencia de las mujeres en las instituciones políticas, fueron también elementos distintivos del movimiento de mujeres de los años ochenta y principios de los noventa.

Lo cierto es que este clima de apertura política y jurídica propició una etapa, corta pero muy rica, de libertades democráticas, casi sin parangón en el mundo árabe en aquel momento, que permitió el desarrollo de una dinámica sociedad civil y de un heterogéneo sistema de partidos políticos de ideología muy diversa, dentro del cual descollará el islamista Frente Islámico de Salvación (FIS). Legalizado el 6 de septiembre de 1989²5, el FIS adquirirá una relevante capacidad de movilización que le permitió alzarse con la victoria en las elecciones locales de 1990, pero su encarnizada lucha antisistema, su rivalidad con el partido hegemónico (FLN), su

${ }^{3}$ Sobre el Código de la familia vid. C. PÉREz Beltrán, Estatuto jurídico de la mujer argelina: matrimonio y divorcio, Granada, Grupo de Investigación Estudios Árabes Contemporáneos, 1991, pp. 106-120, y «El Código argelino de la familia: estudio introductorio y traducción», en El Magreb. Coordenadas socioculturales, Granada, Adhara, 1995, pp. 375-411.

${ }^{24}$ Entre otras novedades, se uniformiza la edad de matrimonio en diecinueve años para ambos sexos, se elimina el deber de obediencia de la esposa, se limita la posibilidad del hombre de ser polígamo, pierde importancia la presencia del tutor (aunque no desaparece), se unifican los deberes matrimoniales, se introducen nuevas causas de divorcio judicial, se preserva la custodia de la mujer trabajadora, se reserva el derecho a la vivienda a la madre que tiene la custodia, etc. Vid. C. Pérez Beltrán, «Nuevas modificaciones del Código argelino de la familia: estudio introductorio y traducción», Miscelánea de Estudios Árabes y Hebraicos. Sección Árabe-Islam, vol. 54 (2005), pp. 143-167.

${ }_{25}$ Sobre la creación del FIS y sus estrategias vid. L. THIEUx, Islamismo y democracia en Argelia. Francia y Estados Unidos frente al conflicto, Madrid, Ediciones del Oriente y del Mediterráneo, 2008, pp. 33-79. 
rígido concepto de orden moral y sus planteamientos muy conservadores irán unidos a un incremento de la violencia contra las mujeres en el espacio público, aunque es cierto que este fenómeno no debe ser achacado exclusivamente a este partido, ya que se encuentran implicados otros grupos políticos e incluso instancias institucionales ${ }^{26}$. Lo cierto es que a principios de los años noventa el debate sobre la violencia de género conoce un importante desarrollo debido a un preocupante incremento de actos de intimidación y de violencia física y psicológica contra las mujeres ${ }^{27}$, sobre todo en el espacio público (estudiantes universitarias, profesoras, feministas, mujeres que viven solas, deportistas, trabajadoras, actrices, mujeres sin pañuelo, etc.), con el fin de limitar sus libertades individuales o sus derechos profesionales.

Pero lo peor estaba por llegar. El proceso de transición iniciado a finales de los años ochenta será suprimido bruscamente mediante el golpe de estado de enero de 1992, que «protagonizado por el ejército y refrendado por ciertos sectores laicos de la sociedad civil que sirvieron de plataforma legitimadora, tenía por finalidad inmediata evitar una segura victoria del FIS en la segunda vuelta de las elecciones legislativas y, a más largo plazo, reubicar al ejército y a sus redes clientelares en los resortes del poder político y económico. El balance posterior es aterrador: más de 150.000 muertos en una guerra sucia en donde el ejército y las fuerzas de seguridad del Estado han desempeñado un papel más que dudoso y cuyas consecuencias más violentas aún sigue sufriendo el país hoy en día ${ }^{28}$. Como sostiene Y. Zoubir, tras la anulación de las elecciones legislativas, «el régimen argelino no contaba con ninguna estrategia con la que superar la crisis política sobrevenida. La debilidad del gobierno condujo a un agravamiento de la violencia que casi destruyó al Estado entre 1993 y 1995» ${ }^{29}$.

\footnotetext{
${ }^{26}$ Salima Mellah afirma que existe una intencionalidad política en achacar al FIS todos los actos de violencia ocurridos entre 1989 y 1991 y señala otra serie de fuerzas que estuvieron implicadas, como son el propio Departamento de Información y Seguridad, infiltrado en el movimiento islamista para radicalizarlo, y otros grupos diversos como al-Hîyra wa-lTakfìr, compuesto en su mayoría por antiguos veteranos de la guerra de Afganistán. Vid. S. MelLaH, Le mouvement islamiste algérien entre autonomie et manipulation, Comité Justice pour l'Algérie, dossier núm. 19, pp. 14-15.

${ }_{27}$ Para una descripción más detallada de los principales actos de violencia cometidos contra las mujeres durante estos años vid. la tesis doctoral de R. BELMADANI, Género, ciudadanía, derechos fundamentales y desarrollo: análisis de las dimensiones de género en el desarroIlo. El caso de Argelia, Valencia, Universidad de Valencia, 2014, pp. 306-315.

${ }_{28}$ C. Pérez Beltrán, «Democracia, sociedad civil y derechos humanos en el Magreb», Nova África, vol. 12 (2003), pp. 85-86.

29 Apud A. Aghrout, «Reformas políticas en Argelia. ¿Cambios verdaderos o meros
} 
Y como suele ocurrir en los conflictos armados, las mujeres se convirtieron en arma de guerra, ya que «la violencia contra la población civil en los conflictos armados no puede entenderse desligada de aquella violencia inherente al patriarcado» ${ }^{30}$. La violencia contra las mujeres, especialmente los secuestros y las violaciones, perpetrada tanto por los grupos islamistas armados como por las fuerzas de seguridad del Estado o los denominados «grupos de autodefensa» o «patriotas», alcanzó dimensiones alarmantes. En este sentido, Saida Benhadibes, presidenta de la Asociación Nacional de Solidaridad con la Mujer Rural, señala ${ }^{31}$ que la cantidad de mujeres violadas entre 1992 y 1997 es bastante superior a la cifra oficial situada en 7.000, mientras que la organización International Women's Rights Action Watch ${ }^{32}$ considera que el número de raptadas durante este conflicto armado era igualmente muy superior a las 2.048 que señalaba el Ministerio del Interior. El motivo principal de este desajuste de cifras está relacionado con el fenómeno de la «estigmatización de las víctimas» ${ }^{33}$ debido al rechazo social y al deshonor que para la familia patriarcal argelina supone esta dura realidad, con lo cual muchas mujeres optaron por el silencio, la resignación y el anonimato.

Durante toda la década de los años noventa del siglo xx la población sufrió las nefastas consecuencias del conflicto armado, a pesar de la normalización política e institucional que supuso la elección como presidente de Liamine Zéroual (1995-1999) que, no obstante, optó por una política «erradicadora» que tenía por objetivo la total exclusión y eliminación del FIS del juego político. Sólo a partir de la elección del actual presidente Abdelaziz Bouteflika, en el poder desde las elecciones del 15 de abril de 1999, y su polémica Ley de Concordia Civil ${ }^{34}$ (julio de 1999), que tenía por objetivo la

ajustes?, en Y. H. ZoubiR y H. AmIRAH (coords.), El Magreb. Realidades nacionales y dinámicas regionales, Madrid, Síntesis, 2008, p. 65.

30 M. VIlLELlas ARIÑo, «La violencia sexual como arma de guerra», Quaderns de Construcció de Pau, vol. 15 (2010), p. 13.

31 Apud R. Belmadani, Género, ciudadanía, derechos fundamentales y desarrollo..., op. cit., p. 316.

32 Vid. su informe «Algeria, Initial report dated 1 September 1998», disponible en http://hrlibrary.umn.edu/iwraw/algeria.htm (consultado el 9 de junio de 2017).

33 Vid. Amnesty International, Algérie. Des reformes globales sont necessaires por mettre un terme à la violence sexuelle et à la violence liée au genre contre les femmes et les jeunes filles, London, 2014.

34 Según su artículo primero: «La Ley tiene por objeto instituir medidas particulares encaminadas a establecer salidas apropiadas a personas implicadas en actos de terrorismo o subversión que expresen su voluntad de abandonar, con toda conciencia, sus actividades criminales y darles la oportunidad de concretar esta aspiración por la vía de la reinserción civil en la sociedad». Ley 99/08, del 13 de julio de 1999, relativa al restablecimiento de la concordia civil, Journal Officiel de la République Algérienne/Al-Ŷrarida al-Rasmiyya li-l-Ŷumbūriyya 
amnistía y la reinserción social de miembros de los grupos armados (principalmente del Ejército Islámico de Salvación, exentos de delito de sangre), la situación en Argelia empieza a conocer un significativo cambio.

En cuanto al tema que nos ocupa, a partir del acceso de Bouteflika al poder, el debate se articula en torno a tres cuestiones principales: a) el reconocimiento del estatus de víctima de terrorismo a las mujeres que sufrieron violación durante el conflicto armado de los años noventa; $b$ ) la necesidad de visibilizar y concienciar sobre este grave problema, y c) la urgencia de adoptar una legislación específica para luchar contra la violencia de género en cualquiera de sus manifestaciones; tema este último que trataremos en el siguiente epígrafe.

El primer asunto señalado $a$ ) está directamente relacionado con la protección de las mujeres víctimas con el fin de garantizar su derecho a la justicia, su reinserción social y todo tipo de ayuda, indemnización o reparación, como cualquier otra persona que haya sido víctima del terrorismo. A pesar de la intensa campaña orquestada por la sociedad civil (asociaciones de mujeres, asociaciones de víctimas de terrorismo, asociaciones de derechos humanos, etc.), la lucha por este reconocimiento no fue fácil; incluso la «Carta para la Paz y la Reconciliación Nacional» ${ }^{35}$, aprobada por referéndum el 29 de septiembre de 2005, que incluía nuevas medidas de gracia a los agentes del Estado y demás personas implicadas en actos violentos y/o delitos durante la guerra civil, no hacía referencia alguna a las mujeres violadas. Finalmente, y gracias a la presión social, el primer ministro Adelmalek Sellal anunciaba a principio de febrero de 2014 la adopción del Decreto Ejecutivo $14 / 26^{36}$, cuyo artículo segundo señala: «Igualmente será considerada como víctima de acto de terrorismo toda mujer que haya sufrido viola-

al-Ŷaza’ iriyya, 46 (13 de julio de 1999), pp. 3-7 (francés) y 3-8 (árabe). Vid. F. BOUKRAA et al., La Concordia civil argelina a través de la prensa española (El País y La Vanguardia), Barcelona, Fundació Solidaritat UB de la Universitat de Barcelona, 2009, pp. 25-39.

35 Orden núm. 06/01, del 28 Muharram de 1427, correspondiente al 27 de febrero de 2006, portando la puesta en marcha de la Carta para la Paz y la Reconciliación Nacional, Journal Officiel de la République Algérienne, 11 (28 de febrero de 2006), pp. 3-7. Sobre esta Ley vid. R. Bustos, «Referéndum de reconciliación nacional. Argelia 2005», Anuario IEMed del Mediterráneo, 2006, pp. 122-124; D. GHANEM-YAZBECK, «Algeria on the Verge: What Seventeen Years of Bouteflika Have Achieved», disponible en http://carnegie-mec.org/2016/04/28/algeria-on-verge-what-seventeen-years-of-bouteflika-bave-achieved/ ixuj (consultado el 18 de junio de 2017); R. TLEmÇANI, «Algeria Under Bouteflika. Civil Strife and National Reconciliation», Carnegie Papers, 7 (2008), disponible en bttp://carnegieendowment.org/files/cmec7_tlemcani_algeria_final.pdf (consultado el 18 de junio de 2017), y H. ZerRouKI, «L'Álgérie après la Charte pour la Paix et la Réconciliation Nationale», Recherches Internationales, vol. 75, núm. 1 (2006), pp. 25-40.

36 Decreto Ejecutivo (Marsūm Tanfīīī) 14/26, Journal Officiel de la République Algé- 
ción por parte de un terrorista o un grupo terrorista», abriendo el camino a las correspondientes indemnizaciones económicas y demás ayudas públicas.

En cuanto a la visibilización y toma de conciencia $b$ ), la lucha se centra principalmente en la violencia intrafamilar, ya que «la mayor parte de las víctimas de violencia en Argelia sufren una "violencia de proximidad" en el seno de la familia o del hogar» ${ }^{37}$. De esta forma, según el Instituto Nacional de Salud Pública (INSP), el 64,5 por 100 de los casos registra$\operatorname{dos}^{38}$ se producen en el domicilio familiar y el 50 por 100 del total de las denuncias se refieren a agresiones cometidas por el marido o el exmarido, con el agravante, además, de que la mayor parte de las mujeres agredidas optan por el silencio y no llegan a interponer denuncia, ya que la violencia contra las mujeres y las relaciones de desigualdad son asumidas y normalizadas por gran parte de la sociedad patriarcal de Argelia, incluyendo a las propias víctimas. En este sentido, una encuesta ${ }^{39}$ realizada en el año 2008 por la Oficina Nacional de Estadística de Argelia, financiada por UNICEF, revelaba que el 67,9 por 100 de las mujeres argelinas aceptaban la violencia de su marido y que el 59 por 100 de las encuestadas, con edades entre quince y cuarenta y nueve años, consideraban que el marido tenía el derecho de golpear o castigar a su esposa por diversas causas.

Para acercarnos a la incidencia de este grave problema social, una de las principales dificultades es la ausencia de fuentes estadísticas fiables, sobre todo conforme nos alejamos en el tiempo, aunque actualmente sigue siendo un grave problema que afecta especialmente al medio rural en donde no existe un control adecuado de datos. No solamente muchas mujeres, debido a diversos condicionantes, no interponen denuncias por violencia de género, sino que numerosos casos no son considerados como tales por las autoridades del orden público, lo cual repercute en las estadísticas oficiales. A pesar de ello, contamos con algunos datos aproximativos que nos permiten acercarnos al problema; de este modo, de enero

rienne/Al-Ŷrañda al-Rasmiyya li-l-Ŷmbūriyya al-Ŷazāiriyya, 5 (2 de febrero de 2014), pp. 19-20 (francés) y 21-22 (árabe).

37 D. Iamarene Djerbal y F. Oussedik, «Le réseau Wassila, un colllectif algérien pour les droits des femmes et l'égalité», Nouvelles Questions Féministes, vol. 33, núm. 2 (2014), p. 137.

38 Se refiere al año 2005. Datos tomados de E. Josse, Les violences conjugales. Quelques repères, Argel, 2007, p. 7.

39 Vid. Balsam, Femmes et violence en Algérie, septiembre de 2010, p. 3, y M. FauLIOT-MARJANY, «L'Algérie se dote d'une loi criminalisant les violences contre les femmes», CNews, 10 de diciembre de 2015, disponible en http://www.cnews. $\mathrm{fr} /$ monde/video/lalgerie-se-dote-dune-loi-criminalisant-les-violences-contre-les-femmes-146467 (consultado el $11 \mathrm{de}$ junio de 2017). 
de 2004 a febrero de 2006, los servicios de seguridad registraron 1.500 casos de violencia conyugal, 400 abusos sexuales y dieciséis mujeres asesinadas ${ }^{40}$. Dos años después, en 2008, los servicios de policía registraron ya 9.517 casos de violencia contra las mujeres, aunque dichas cifras se referían solamente al ámbito urbano, que es en donde actúa la policía, mientras que el medio rural seguía quedando al margen. Conforme avanzamos en el tiempo los datos suelen ser más específicos y durante el año $2015^{41}$ la Dirección General de la Seguridad Nacional (DGSN) registró 9.663 casos de violencia contra las mujeres, de los cuales, 6.891 casos correspondían a violencia física, seguida de 2.333 casos de malos tratos, 282 casos de violencia sexual, 10 casos de incesto y 119 casos de acoso sexual. A ellos se añadía 34 casos de mujeres asesinadas y cuatro casos de apaleamiento con resultado de muerte. Según esta misma fuente, la mayoría eran mujeres casadas $(56,12$ por 100$)$, lo cual demuestra que la violencia conyugal es la más persistente o, al menos, la más visible, seguidas de solteras $(26,37$ por $100)$, divorciadas $(10,87$ por 100) y viudas $(5,95$ por 100$)$.

Estos datos son sólo aproximativos de una realidad mucho más dura, más usual y más extendida, anclada en la cotidianidad de muchas mujeres argelinas que sufren en silencio y abnegadamente diversos actos de violencia física, moral o psicológica, incluidas las amenazas, las coacciones, las agresiones a su libertad sexual o la privación arbitraria de su libertad. A ello se añaden otros factores, como la estigmatización social de las víctimas, la dependencia económica de éstas, los complejos procesos judiciales, la falta de una intervención ágil y adecuada de la policía, la escasez de centros de acogida ${ }^{42}$ y otras infraestructuras de apoyo a las víctimas, las presiones fami-

${ }^{40}$ Datos tomados de B. GHECHIR, «La violence contre les femmes en Algérie. Une synthèse de la situation en Algérie préparée par le Ligue Algérienne des Droits de l'Homme en vue de préparer le travail de la rapporteure des Nations Unies», disponible en bttp:// www.genreenaction.net/La-violence-contre-les-femmes-en-Algerie.html (consultado el 11 de junio de 2017).

${ }^{41}$ Comparativamente hablando, los datos distan mucho de países como España, que cuenta con una trayectoria de lucha contra la violencia de género mucho más amplia y articulada. Según datos del Instituto Nacional de Estadística, en el año señalado (2015) se registraron en España 27.624 mujeres víctimas de violencia de género correspondientes a los asuntos en los que se habían dictado medidas cautelares u órdenes de protección. Vid. http://www. ine.es/prensa/np972.pdf. En cuanto a víctimas mortales, durante el mismo año, el Ministerio de Sanidad y Asuntos Sociales señala la cifra de sesenta. Vid. http://www.violenciage nero.msssi.gob.es/violenciaEnCifras/boletines/boletinAnual/docs/B_E_Anual_2015.pdf(consultado el 11 de junio de 2017).

42 En Argelia solamente existen tres centros públicos de acogida a mujeres víctimas de violencia para una población estimada de 41 millones de habitantes. Por su parte, los centros privados, dependientes de asociaciones, carecen de la ayuda necesaria por parte de las 
liares y la consideración de la violencia intrafamiliar como un «asunto privado», entre otros motivos que no podemos abordar en este trabajo.

Por ello, desde hace al menos una década han surgido diversas iniciativas, tanto a nivel gubernamental como de la propia sociedad civil. Entre las primeras cabe destacar la puesta en marcha en 2006 de la Estrategia Nacional de Lucha contra la Violencia contra las Mujeres, dependiente del Ministerio de la Familia y la Condición Femenina, cuya acción se articula en torno a tres ejes principales ${ }^{43}$ : asegurar la protección y la seguridad de las mujeres víctimas desde el punto de vista legal y de la salud; favorecer su reinserción social y económica, y poner en marcha medidas y reformas jurídicas y constitucionales. En cuanto a la acción de la sociedad civil, en el ámbito que nos ocupa destacan tres importante redes. La primera es la Red Nacional de Centros de Escucha sobre las Violencias contra las Mujeres, creada en 2008 con el objetivo de atender y dar voz a las mujeres víctimas de violencia, así como sensibilizar a la sociedad mediante la difusión de testimonios personales y de resultados de investigación ${ }^{44}$. La segunda, aparecida en octubre de 2010, se denomina Red Wassila ${ }^{45}$ y su acción se organiza en torno a tres ejes principales: desarrollar una política eficaz de apoyo a las mujeres víctimas en todas sus necesidades, formar a especialistas en violencia de género y exigir una legislación que criminalice cualquier tipo de violencia contra las mujeres. En cuanto a sus proyectos de acción, cabe destacar, en primer lugar, un importante centro de escucha telefónica a partir de la atención personaliza a mujeres y niños, ayuda jurídica, acompañamiento médico y diversas campañas de sensibilización. Finalmente, la última red en aparecer ha sido ¡Stop a la Violencia! Los Derechos de las Mujeres Ya ${ }^{46}$, en 2010, cuyo principal objetivo es exigir al Estado la adop-

instituciones. Vid. el informe realizado por Human Rights Watch, Your Destiny is to Stay with Him: State Response to Domestic Violence in Algeria, disponible en bttps://www. brw. org/report/2017/04/23/your-destiny-stay-him/state-response-domestic-violence-algeria (consultado el 11 de junio de 2017).

${ }^{43}$ Vid. Stratégie Nationale de Lutte contre la Violence à l'égard des Femmes, Argel, Ministère Délégué Chargé de la Famille et de la Condition Féminine, s.d.

44 Vid. el siguiente informe basado en los datos de 546 casos de mujeres víctimas de violencia que han sido recopilados en trece centros de escucha repartidos por la geografía argelina, Les violences contre les femmes en Algérie. Deuxièmes résultats, septiembre de 2010.

${ }^{45}$ Entre otras asociaciones, forman parte de esta red las siguientes: Asociación de Ayuda a las Víctimas de Violencia contra las Mujeres y los Niños, SOS Kinderdorf International, Tharwa Fatma N'Soumer, Asociación para la Emancipación de las Mujeres y otros colectivos de profesionales relacionados con la salud, la justicia y los derechos humanos. Vid. D. Iamarene Djerbal y F. OussediK, «Le réseau Wassila...», op. cit., pp. 136-140.

${ }^{46}$ Entre otras asociaciones, pertenecen a esta red: la Asociación Argelina de Planificación Familial, la Asociación de Defensa y Promoción de los Derechos de la Mujer, Amusnaw de 
ción de leyes que penalicen severamente a los agresores y que protejan adecuadamente a las mujeres de cualquier manifestación de violencia.

Tras el estallido de la denominada «Primavera Árabe» (2011) y sus reivindicaciones de cambio político y económico, la violencia contra las mujeres ha seguido articulando a buena parte de la sociedad civil argelina comprometida con las libertades democráticas, la igualdad de género y los derechos humanos. En buena medida esto también se justifica por el hecho de que los jóvenes y las mujeres se convirtieron en los grandes protagonistas durante estas olas de cambio, ya que ellos eran los colectivos sociales que más habían sufrido el deterioro de las condiciones de vida, el paro y la precariedad. Las revueltas argelinas ${ }^{47}$ no acabaron, como en otros países de la zona (Túnez, Libia, Egipto), en un cambio de régimen, pero las dinámicas de protesta alcanzaron niveles muy preocupante, sobre todo en la zona norte de Argel, Orán y Kabilia, y provocaron una rápida respuesta del régimen político que, como medida de contención, puso en marcha una serie acciones socioeconómicas y concesiones políticas, como la bajada de los precios de productos básicos, el aumento del salario de los funcionarios y las pensiones de los jubilados, el levantamiento del estado de emergencia (vigente desde 1992), el adelanto de las elecciones legislativas a mayo de 2012, la dinamización del debate en torno a la reforma constitucional y la promulgación de una serie de leyes relacionadas con las libertades públicas, que pretende simbolizar un nuevo talante aperturista del régimen. En esta misma dinámica hay que situar la última gran reforma constitucional (tercera reforma de la «era Boutflika») del 6 de marzo de 2016, que proscribe cualquier tipo de violencia física o moral (art. 40) ${ }^{48}$ e introduce,

Tizi Uzu, la Asociación de Ayuda a las Víctimas de Violencia contra las Mujeres y los Niños, Centro de Información y Documentación de los Derechos de las Mujeres y los Niños, Djazairouna, Rachda-Agrupación Argelina contra la Hogra y para los Derechos de las Argelinas, Tharwa Fatma N'Soumer, Red Wassila, etc. Vid. H. AmEYA, «Stop à la violence, des droits des femmes maintenant Le collectif se prépare pour un plaidoyer», disponible en $b t t p: / / w w w . g e n-$ reenaction.net/Img/pdf/Stop_a_la_violence.pdf (consultado el 11 de junio de 2017).

47 Sobre las revueltas del 2011 en Argelia vid. A. Aghrout y L. Murillo, «La "Primavera Árabe” de Argelia. ¿Tanto para nada?», Foro Internacional, vol. 52, núm. 2 (2012), pp. 412-433; L. Dris-Ait Hamadouche, «L'Álgerie face au "printemps arabe”: l'equilibre par la neutralisation des contestations», Confluences Méditerranée, vol. 2 (2012), pp. 55-67, disponible en https://doi.org/10.3917/come.081.0055; L. THIEux, «El papel de la sociedad civil argelina en las perspectivas de cambio político en Argelia», Revista General de Derecho Público Comparado», núm. 11 (2012), y F. VOLPI, «Algeria versus the Arab Spring», Journal of Democracy, vol. 24, núm. 3 (2013), pp. 104-115.

48 Art. 40: «El Estado garantiza la inviolabilidad del ser humano. Cualquier forma de violencia física o moral o cualquier atentado contra la dignidad están prohibidos. Los tratos crueles, inhumanos o degradantes son castigados por la ley». 
además, dos artículos (arts. 35 y 36$)^{49}$ que comprometen al Estado con la promoción de los derechos políticos, económicos e institucionales de las mujeres, a fin de alcanzar la igualdad entre todos los ciudadanos (art. 32) ${ }^{50}$.

\section{EL DEBATE POLÍTICO SOBRE LA LEY SOBRE VIOLENCIA CONTRA LAS MUJERES}

Como señalamos anteriormente, uno de los grandes ejes que articula el debate sobre la violencia contra las mujeres durante la última década y media en Argelia es la necesidad de adoptar una legislación específica y eficaz que ayude a prevenir, condenar y penalizar cualquier acto violento por razón del género. En este sentido, las primeras modificaciones puntuales del Código Penal tuvieron lugar durante los años 2004 (Ley 04/15, de 10 de noviembre de 2004) y 2006 (Ley 23/06, de 20 de diciembre de 2006), aunque solamente incidían en determinados aspectos del abandono del domicilio conyugal o la utilización de la fuerza o intimidación del esposo, que analizaremos más adelante.

Sin embargo, el gran debate social y político, que logró obtener mejores resultados desde el punto de vista legal, tuvo lugar durante el año 2015, ya que propiciará la adopción de la Ley núm. 15/19, principal objeto de este estudio. No obstante, no fue un asunto fácil debido a la fractura ideológica dentro de la cámara baja del país, la Asamblea Popular Nacional (APN), lo que provocará un retraso de nueve meses hasta su adopción definitiva. Como proyecto de ley fue debatido y finalmente aprobado por la APN el 5 de marzo, pero contando con la oposición más o menos virulenta de algunas formaciones políticas, como la Alianza para una Argelia Verde (AAV), una coalición de partidos islamistas ${ }^{51}$ creada exprofeso para las elecciones legislativas de 2012 y que lograron hacerse con 48 escaños $^{52}$ (10,6 por 100), de

49 Art. 35: «El Estado vela por la promoción de los derechos políticos de la mujer, aumentando sus posibilidades de acceso a la representación en las asambleas elegidas». Art. 36: «El Estado vela para promover la paridad entre hombres y mujeres en el mercado de empleo. El Estado fomenta la promoción de la mujer a puestos de responsabilidad en las instituciones y administraciones públicas, así como a nivel de empresas».

50 Art. 32: «Los ciudadanos son iguales ante la ley, sin que pueda prevalecer discriminación alguna por razón de nacimiento, raza, sexo u opinión, o cualquier otra condición o circunstancia personal o social».

${ }^{51}$ Los partidos son: Movimiento de la Sociedad por la Paz (HAMAS), Movimiento por la Reforma Nacional y Movimiento del Renacimiento Islámico/Al-Nahda.

52 Vid. A. Mañé, L. Thieux y M. Hernando de Larramendi, Argelia en la encrucija- 
los cuales 15 ocupados por mujeres. Tampoco fue el único sector de oposición; junto a ellos se posicionaron otros partidos islamistas, como el Frente de la Justicia y el Desarrollo/Al-Adala (8 escaños y 1,7 por 100) y diversos miembros independientes. Por su parte, otros partidos de ideología muy diferente, como el Partido de los Trabajadores (24 escaños y 3,7 por 100), de tendencia internacionalista-troskista y partidario de la abrogación total del Código de la familia, optaron por la abstención, ya que consideraban una propuesta demasiado tímida cuya única finalidad era avalar la política oficial del régimen en cuestión de género. Por su parte, otros partidos de la oposición y partidarios igualmente de la abrogación del Código de la familia, como el Frente de Fuerzas Socialistas (27 escaños y 5,8 por 100), optaron por votar a favor del proyecto de ley porque, a pesar de sus limitaciones y su carácter parcial, consideraban que era un primer paso importante para proteger a las mujeres de diversas manifestaciones violentas. En general, ésta es la opinión de la mayor parte de los agentes sociales implicados en la lucha contra la violencia de género en Argelia, a la espera de que próximamente pueda ser adoptada una ley orgánica mucho más articulada, sólida y contundente. En palabras de Soumia Salhi, militante de la Asociación para la Emancipación de la Mujeres, «la ley no nos satisface totalmente, pero es un primer paso, un instrumento a favor de las víctimas» ${ }^{53} \mathrm{y}$, según un comunicado de Amnistía Internacional, «las enmiendas propuestas constituyen un paso importante en la dirección correcta, pero no deben en ningún caso sustituir a reformas integrales para prevenir, sancionar y erradicar la violencia sexual y por motivos de género en Argelia» ${ }^{54}$. Otras manifestaciones se muestran incluso más optimistas, como la de Dalila Aoudj, presidenta de la Asociación Rachda-Agrupación Argelina contra la Hogra y para los Derechos de las Argelinas, quien afirma: «Es una cobertura jurídica que va a ayudar realmente a la mujer a tener más derechos y más equilibrio, tanto en el interior de su hogar familiar como en los lugares públicos» ${ }^{55}$.

da: condicionantes, tendencias y escenarios, Madrid, Fundación Alternativas-Ministerio de Defensa, 2016, p. 40.

53 Apud S. Chellali, «Algérie: la loi criminalisant les violences faites aux femmes, jetée aux oubliettes?», Jeune Afrique, 28 de agosto de 2015, disponible en bttp://www.jeuneafrique.com/260203/politique/algerie-loi-criminalisant-violences-aux-femmes-jetee-aux-oubliettes/ (consultado el 16 de junio de 2017).

54 «Algérie: nécessité d'une réforme globale contre les violences liées au genre», Amnesty International Déclaration Publique, 9 de diciembre de 2015, disponible en bttps://www. amnesty.org/fr/documents/mde28/3044/2015/fr/ (1 consultado el 6 de junio de 2017).

55 «Algérie: la loi contre les violences faites aux femmes adoptée», disponible en http://www.rfi.fr/afrique/20151211-algerie-loi-contre-violences-faites-femmes-adoptee-parlement-senat-islamistes (consultado el 16 de junio de 2017). 
Por su parte, los argumentos esgrimidos en contra del proyecto de ley son bastante reaccionarios, inmersos en una visión rígida de la moral islámica e impregnados de connotaciones machistas cuando no misóginas. Por ejemplo, la diputada de la AVV, Naamane Belaouar, señalaba que el texto es «contrario a los preceptos coránicos y tiende a distorsionar a la familia» ${ }^{56}$, mientras que el diputado independiente Ahmed Khelif lo consideraba «un amordazamiento de las libertades del hombre y una forma de convertir en lícitas las relaciones extraconyugales, puesto que será más simple tener una amante que estar casado y correr el riesgo de estar perseguido por cualquier motivo» ${ }^{57}$; por su parte, un representante de Al-Adala culpabilizaba a las mujeres del acoso sexual al considerar que el no respeto de la vestimentaria islámica (velo y ropa recatada) en los lugares públicos era la principal causa de este problema, al tiempo que considera que el objetivo de esta ley era vengarse del esposo ${ }^{58}$. Otros argumentos contrarios a la adopción de la Ley incidían en la imposición de normas occidentales, la introducción de leyes contrarias a la cultura nacional argelina, la intrusión en la intimidad del matrimonio, la promoción de las relaciones extraconyugales, etcétera.

Estos debates, bastantes enconados, se encontrarán presentes en los medios de comunicación durante varios meses, achacando la causa del bloqueo de la ley a los partidos islamistas, aunque éstos argumentaban a su favor, y con razón, que los motivos reales debían ser otros, ya que ellos eran minoría en el Parlamento, mientras que el partido presidencial (FLN) ocupaba el 45 por 100 de los escaños. En cualquier caso, la presión de la sociedad civil (asociaciones de mujeres, derechos humanos, juristas, médicos, etc.), junto a la repercusión mediática que alcanzaron algunos actos de violencia contra las mujeres acometidos en aquella época, como la violación colectiva de la inmigrante camerunesa Marie Simone D. en Orán (1 de noviembre de 2015) o el asesinato de una joven que rehusó las insinuaciones sexuales de un automovilista ( 8 de noviembre de 2015), propiciaron la aprobación definitiva de la Ley núm. 15/19 por parte del Consejo de la Nación (Cámara Alta) el día 30 de diciembre de 2015, presidido por el ministro de Justicia, Abdelkader Benssalah, y el ministro de Relaciones con el Parlamento, Tahar Khaoua.

56 «Algérie: Une loi contre la violence faite aux femmes», 20 Minutes, 6 de marzo de 2015, disponible en http://www.20minutes.fr/monde/1556383-20150306-algerie-loi-contre -violence-faite-femmes (consultado el 16 de junio de 2017).

${ }^{57}$ Ibid.

58 Ibid. 


\section{CONTENIDO DE LA LEY NÚM. 15/19, DEL 30 \\ DE DICIEMBRE DE 2015, MODIFICANDO Y COMPLETANDO EL CÓDIGO PENAL}

La Ley 15/19, denominada por los actores sociales y políticos como «Ley sobre violencia contra las mujeres», tiene por objetivo introducir en el Código Penal argelino cinco nuevos artículos (arts. 266 bis, 266 bis 1, 330 bis, 333 bis 2 y 333 bis 3) y modificar otros cuatro ya existentes (arts. 330, 341 bis, 368 bis y 369), a fin de penalizar diversos actos de violencia individual que se ejercen en el ámbito familiar y en el espacio público. Para valorar más adecuadamente los avances que supone esta Ley, distinguiremos diversos apartados atendiendo a las principales formas o manifestaciones de la violencia que recoge la norma.

\section{Violencia física en el ámbito conyugal}

La violencia intrafamiliar ejercida entre los cónyuges es, posiblemente, la principal preocupación que denota la Ley 15/19, ya que, como señalamos anteriormente, la mayor parte de las víctimas de violencia, así como de las denuncias que se interponen por ello, se producen en el espacio familiar. De esta forma, el art. 266 bis establece diversas sanciones penales, dependiendo de la gravedad de los daños provocados al cónyuge o excónyuge, resida éste o no en el domicilio de la víctima. Dichas penas oscilan: de uno a tres años de cárcel si la agresión física no provoca una enfermedad o una incapacidad para trabajar superior a quince días; de dos a cinco años de cárcel si provocan una incapacidad total para trabajar por un periodo de tiempo superior a quince días; de diez a veinte años de cárcel si la agresión provoca la pérdida o amputación de algún miembro o la pérdida de la vista o cualquier otra invalidez permanente, y, finalmente, cadena perpetua si el golpe o la herida provocan la muerte de forma intencionada o no.

Sin embargo, ya el art. 266 bis introduce el tema más polémico de toda la ley: el perdón de la víctima (safh al-dahiyya) y sus atenuantes, de tal forma que el agresor puede salir indemne del proceso en los dos primeros casos señalados (agresión física con incapacidad o no para trabajar por un periodo de quince días), mientras que en el tercer caso (agresión con pérdida de miembro o invalidez) el perdón de la víctima puede reducir la pena de cár- 
cel a la mitad. Muchas han sido las críticas recibidas por parte de los agentes sociales porque, teniendo en cuenta las características de la familia tradicional argelina, las mujeres pueden verse sometidas a presiones muy diversas para lograr de ellas el perdón de su agresor. Según Amnistía Internacional, «tal disposición no sólo ignora la realidad de las relaciones de poder y desigualdad entre hombres y mujeres, sino que expone, asimismo, a las mujeres a un mayor riesgo de violencia y de recurso a métodos coercitivos para que retiren su denuncia» ${ }^{59}$. Para Saoumia Salhi, militante de la Asociación para la Emancipación de la Mujer, esta cláusula es «una derrota de la palabra de las mujeres y un mensaje de impunidad para los agresores» ${ }^{60}$.

\section{Violencia verbal o psicológica en el ámbito conyugal}

Junto a la violencia física, la violencia verbal o psicológica en el ámbito familiar es penalizada a través del art. 266 bis 1 de la Ley 15/19, el cual establece una pena de uno a tres años de cárcel para quien cometa contra su cónyuge o excónyuge cualquier tipo de agresión verbal o psicológica reiterada, que atente a la dignidad de la víctima o que afecte a su integridad. Al igual que la agresión física, se especifica que la pena se aplicará al agresor independientemente de que resida o no en el mismo domicilio de la víctima y, de igual forma, se introduce la polémica fórmula del perdón, que en el caso de la violencia verbal o psicológica comporta el fin del procesamiento penal.

\section{Violencia física y sexual en el espacio público}

No solamente el ámbito intrafamiliar es motivo de preocupación por parte de la Ley 15/19, sino que también introduce dentro del Código Penal dos nuevos artículos con la intención de proteger a las mujeres de diversas manifestaciones violentas en el espacio público. El primero de ellos es el art. 333 bis 2, que establece un castigo de dos a seis meses de cár-

59 «Algérie. Opportunité d'une meilleure protection des femmes contre la violence de genre en dépit de propos rétrogrades au parlement», disponible en http//www.amnestyalge rie.org/Algerie/algerie-opportunite-d-une-meilleure-protection-des-femmes-contre-la-violence-de -genre-en-depit-de-propos-retrogrades-au-parlement.html (consultado el 17 de junio de 2017).

60 «La militante Soumia Salhi: l'amendement sur les violences faites aux femmes n'est qu'une maigre avancée», disponible en http://www.huffpostmaghreb.com/2015/03/12/sou mia-salhi-feminisme-algerie_n_6853080.html (consultado el 17 de junio de 2017). 
cel y una multa de 20.000 a 100.000 Dinares Argelinos (DA), o solamente una de ellas, a quien moleste a una mujer en un lugar público mediante actos, palabras o gestos que la ofendan, añadiendo además que dicha pena se duplicará si la víctima tiene menos de dieciséis años. El segundo es el art. 333 bis 3, que impone un castigo de uno a tres años de cárcel y una multa de 100.000 a $500.000 \mathrm{DA}$ al agresor que atente contra la intimidad sexual de la víctima mediante cualquier tipo de agresión cometida furtivamente o con violencia, coerción o amenaza. Además, este mismo artículo eleva la pena a dos y cinco años de cárcel si el agresor es un familiar cercano o en el caso de que la víctima tenga menos de dieciséis años o se encuentre embarazada o padezca algún tipo de enfermedad, minusvalía o discapacidad física o mental.

\section{Acoso sexual}

Uno de los aspectos más novedosos que introduce la Ley 15/19 es la consideración del acoso sexual como un delito, cuestión que hasta el momento no estaba contemplada en el Código Penal de forma tan evidente. De este modo, todo un extenso art. 341 bis estará dedicado a este tipo de violencia. Lo primero que dispone dicho artículo es la consideración de autor de delito de acoso sexual a toda persona que abuse de la autoridad de su cargo o de su profesión mediante órdenes, amenazas, coerción o presión con el propósito de obligar a terceros a cumplir sus deseos sexuales. En el mismo rango, se considera culpable de este delito a quien acose a otros mediante cualquier acto, expresión o comportamiento que suponga un carácter o una insinuación sexual. La pena estipulada para el acoso sexual es de uno a tres años de cárcel y multa de 100.000 a 300.000 DA, aunque existen algunos agravantes como el parentesco del agresor o que la víctima tenga menos de dieciséis años o esté embarazada o padezca alguna enfermedad o discapacidad física o mental, en cuyo caso la pena se eleva a los dos y cinco años de cárcel, y la multa a 200.000 y 500.000 DA. Además, en caso de reincidencia la pena se verá duplicada.

\section{Abandono del domicilio conyugal}

La Ley 15/19 agrava considerablemente las penas relacionadas con el abandono del domicilio conyugal con el fin, sobre todo, de proteger a los 
hijos y a las mujeres casadas. De esta forma, el nuevo art. 330 impone un castigo de seis meses a dos años de cárcel y una multa de 50.000 a 200.000 DA a cualquiera de los dos padres que, sin un motivo suficientemente justificado, abandone el domicilio familiar durante más de dos meses, desatendiendo de esta forma sus obligaciones morales o materiales resultantes de la patria potestad o la tutela legal. Idéntica pena se establece para el marido que abandone deliberadamente a su esposa durante más de dos meses. Este artículo ya había sido modificado en el año 2006 (Ley 23/06, del 20 de diciembre de 2006), pero en aquel entonces las penas eran mucho menores, de dos meses a un año de cárcel, y la multa de 25.000 a 100.000 DA. Además, en el caso del abandono del domicilio conyugal por parte del marido, la anterior Ley de 2006 añadía la apostilla de «sabiendo que está embarazada», con lo cual solamente en esta circunstancia la pena recaía sobre el esposo.

\section{Protección de las posesiones de la esposa}

La Ley 15/19 introduce un nuevo artículo en el Código Civil, el art. 330 bis, que tiene el propósito de proteger las pertenencias de las mujeres casadas. Con tal fin impone una pena de seis meses a dos años de cárcel al esposo que, con el objetivo de disponer de los bienes o recursos de su esposa, ejerza contra ella cualquier tipo de coerción o intimidación. No obstante, de nuevo la norma introduce el atenuante del perdón de la víctima, en cuyo caso se pondría fin al procesamiento penal. En la misma línea, el art. 369 permite que los robos cometidos entre cónyuges puedan ser objeto de medidas de procesamiento penal mediante la denuncia de la persona damnificada. Esto supone un avance respecto a la legislación anterior, ya que sólo contemplaba esta posibilidad a los parientes directos, colaterales o políticos hasta el cuarto grado, pero no a los cónyuges. En todo caso, la norma sigue estipulando que la retirada de la denuncia pondrá fin a estas medidas.

\section{A MODO DE CONCLUSIÓN}

Podemos afirmar que la Ley núm. 15/19, de 30 de diciembre de 2015, es un primer paso para, desde la norma jurídica, luchar contra «todo acto de violencia basado en la pertenencia al sexo femenino que tenga o pueda 
tener como resultado un daño o sufrimiento físico, sexual o psicológico para la mujer», como dicta la Declaración sobre la Eliminación de la Violencia contra la Mujer. En este sentido, la Ley 15/19 es un instrumento que garantiza una mayor protección de las víctimas, pues introduce en el Código Penal penas de cárcel y elevadas multas para los autores de violencia física, verbal y psicológica, tanto en el ámbito intrafamiliar como en el espacio público, al tiempo que criminaliza otros tipos de violencia contra las mujeres, como el acoso sexual y el abandono injustificado del domicilio familiar. Igualmente, al tratarse de penas muy duras que, en el caso extremo del homicidio del cónyuge, puede llegar a la cadena perpetua, esta ley también adquiere un carácter paliativo o preventivo. Sin embargo, la Ley 15/19 también banaliza, en buena medida, la violencia de género, pues, como señala varios agentes de la sociedad civil argelina, la apostilla del «perdón de la víctima» como atenuante de las penas o, incluso, para poner fin al procesamiento penal, se convierte en un elemento discordante, al tiempo que para las víctimas puede suponer presiones familiares de todo tipo.

Por otro lado, la Ley núm. 15/19 introduce modificaciones puntuales dentro de un extenso y complejo Código Penal, y la gravedad de la situación requiere de reformas jurídicas integrales, mucho más elaboradas, mejor articuladas y más comprometidas con los derechos de las mujeres. En este sentido, quizá lo más pertinente sería la promulgación de una ley orgánica centrada en esta materia, anclada en los derechos igualitarios y en la inviolabilidad del ser humano que establece la Constitución argelina en sus arts. 32 y 40, anteriormente señalados.

Esperemos, en todo caso, que la adopción de esta Ley permita a muchas mujeres que viven en silencio y resignación la violencia de género en cualquiera de sus manifestaciones y en cualquier espacio hacer uso de ella e interponer las denuncias oportunas, ya que uno de los graves problemas de la sociedad argelina (posiblemente también de la sociedad mundial) es la normalización de las relaciones violentas, sobre todo en el ámbito conyugal, y la estigmatización de la víctima. Sin lugar a dudas, el cambio de la Ley debe ir aparejado de un cambio de las mentalidades y de las prácticas sociales, ya que la lucha contra la violencia de género, en cualquiera de sus manifestaciones, debe convertirse en un objetivo político de primer orden, independientemente de las divergencias ideológicas y de las especificidades culturales. Los argumentos religiosos, nacionalistas, ideológicos o identitarios no deben servir de coartada para el mantenimiento de un sistema injusto y violento hacia la mitad de la ciudadanía: las mujeres. 


\section{BIBLIOGRAFÍA Y DOCUMENTACIÓN}

\section{Bibliografía}

Aghrout, A., «Reformas políticas en Argelia. ¿Cambios verdaderos o meros ajustes?, en Y. H. Zoubir y H. Amirah (coords.), El Magreb. Realidades nacionales y dinámicas regionales, Madrid, Síntesis, 2008, pp. 63-86.

Aghrout, A., y Murillo, L., «La "Primavera Árabe" de Argelia. ¿Tanto para nada?», Foro Internacional, vol. 52, núm. 2 (2012), pp. 412-433.

AmeYA, H., «Stop à la violence, des droits des femmes maintenant Le collectif se prépare pour un plaidoyer», 11 de junio de 2017, disponible en bttp://www. genreenaction.net/Img/pdf/Stop_a_la_violence.pdf.

Amorós, C., y De Miguel, A. (eds.), Teoría feminista. De la ilustración a la globalización, Madrid, Minerva, 2005.

BABADJI, R., «L'État, les individus et les groupes en Algérie: continuité et rupture», Annuaire de l'Afrique du Nord, vol. 26 (1987), pp. 99-115.

Badran, M., Feminismo en el Islam, Madrid, Cátedra, 2012.

Balsam, Femmes et violence en Algérie, Argel, 2010.

BEKE, D., «La Constitution algérienne de 1989: une passerelle entre le socialisme et l'islamisme?», Afrika Focus, vol. 7, núm. 3 (1991), pp. 241-272.

Belmadani, R., Género, ciudadanía, derechos fundamentales y desarrollo: análisis de las dimensiones de género en el desarrollo. El caso de Argelia, tesis doctoral, Valencia, Universidad de Valencia, 2014.

Bendourou, O., «La nouvelle Constitution algérienne du 28 février 1989», Revue de Droit Publique, vol. 5 (1989), pp. 1305-1328.

BoukraA, F., et al., La Concordia civil argelina a través de la prensa española (El País y La Vanguardia), Barcelona, Fundació Solidaritat UB de la Universitat de Barcelona, 2009.

Bustos, R., El cambio político en Argelia (1988-1992). Análisis sistémico de una transición discordante, tesis doctoral, Madrid, Universidad Complutense, 2003.

— «Referéndum de reconciliación nacional. Argelia 2005», Anuario IEMed del Mediterráneo, 2006, pp. 122-124.

Butler, J., Gender Trouble. Feminism and the Subversion of Identity, New York, Routledge, 1990.

Chellali, S., «Algérie: la loi criminalisant les violences faites aux femmes, jetée aux oubliettes?», Jeune Afrique, 28 de agosto de 2015, disponible en bttp://www. jeuneafrique.com $/ 260203 /$ politiquelalgerie-loi-criminalisant-violences-aux-femmes-jetee-aux-oubliettes/ (consultado el 16 de junio de 2017). 
De Luján Piatti, M., Violencia contra las mujeres y alguien más..., tesis doctoral, Valencia, Universidad de Valencia, 2013.

Dris-Ait Hamadouche, L., «L'Álgerie face au "printemps arabe”: l'equilibre par la neutralisation des contestations», Confluences Méditerranée, vol. 2 (2012), pp. 55-67, disponible en bttps://doi.org/10.3917/come.081.0055.

Fauliot-Marjany, M., «L'Algérie se dote d'une loi criminalisant les violences contre les femmes», CNews, 10 de diciembre de 2015, disponible en bttp://www. cnews.fr/monde/video/lalgerie-se-dote-dune-loi-criminalisant-les-violences-contre-les-femmes-146467 (consultado el 11 de junio de 2017).

Ghanem-Yazbeck, D., «Algeria on the Verge: What Seventeen Years of Bouteflika Have Achieved», disponible en http://carnegie-mec.org/2016/04/28/algeria-on-verge-what-seventeen-years-of-bouteflika-have-achieved/ixuj (consultado el 18 de junio de 2017).

GHECHIR, B. «La violence contre les femmes en Algérie. Une synthèse de la situation en Algérie préparée par le Ligue Algérienne des Droits de l'Homme en vue de préparer le travail de la rapporteure des Nations Unies», disponible en bttp://www.genreenaction.net/La-violence-contre-les-femmes-en-Algerie.html (consultado el 11 de junio de 2017).

Hooks, B., et al., Otras inapropiables: feminismos desde las fronteras, Madrid, Traficantes de Sueños, 2004.

Iamarene Djerbal, D., y Oussedik, F., «Le réseau Wassila, un colllectif algérien pour les droits des femmes et l'égalité», Nouvelles Questions Féministes, vol. 33, núm. 2 (2014), pp. 136-140.

Josse, E., Les violences conjugales. Quelques repères, Argel, 2007.

Mañé Estrada, A., «Ajuste estructural en Argelia. Un diagnóstico equivocado para una difícil reforma», Nación Árabe, vol. 36 (1998), pp. 85-99.

Mañé Estrada, A.; Thieux, L., y Hernando de Larramendi, M., Argelia en la encrucijada: condicionantes, tendencias y escenarios, Madrid, Fundación Alternativas-Ministerio de Defensa, 2016.

Maqueda, M. L., «La violencia de género. Entre el concepto jurídico y la realidad social», Revista Electrónica de Ciencia Penal y Criminología, núm. 8 (2006), disponible en bttp://criminet.ugr.es/recpc/08/recpc08-02.pdf (consultado el 18 de mayo de 2017).

Martín Muñoz, G., «La nueva Constitución argelina: hacia la III República», Revista de Estudios Políticos, vol. 67 (1990), pp. 261-296.

Martín SÁnChez, M., «El género en la "violencia afectiva”: clave para un examen de constitucionalidad», Estudios Constitucionales, vol. 13, núm. 1 (2015), pp. 203-236. 
MellaH, S., Le mouvement islamiste algérien entre autonomie et manipulation, dossier núm. 19, Argel, Comité Justice pour l'Algérie, 2004.

Montabes, J., Las otras elecciones. Los procesos y sistemas electorales en el Magreb, Madrid, Agencia Española de Cooperación Internacional, 1999.

Pérez Beltrán, C., «El Código argelino de la familia: estudio introductorio y traducción», en El Magreb. Coordenadas socioculturales, Granada, Adhara, 1995, pp. 375-411.

- «La Unión Nacional de Mujeres Argelinas: organización femenina de masas», Al-Andalus Magreb, vol. 5 (1997), pp. 295-317.

- «Evolución del movimiento femenino y feminista en Argelia: las mujeres y la política», Estudios de Asia y África, vol. 105, núm. 33 (1998), pp. 75-102.

- «Democracia, sociedad civil y derechos humanos en el Magreb», Nova África, vol. 12 (2003), pp. 85-105.

— «Nuevas modificaciones del Código argelino de la familia: estudio introductorio y traducción», Miscelánea de Estudios Árabes y Hebraicos. Sección ÁrabeIslam, vol. 54 (2005), pp. 143-167.

- «Reformas jurídicas en Argelia tras la primavera árabe: la nueva ley de asociación de 2012», Anaquel de Estudios Árabes, vol. 25 (2014), pp. 181-184, disponible en bttps://doi.org/10.5209/rev_anqe.2014.v25.43797.

- «Pluralismo bajo control: evolución de la Ley de Partidos Políticos en Argelia», Estudios de Asia y África, vol. 52, núm. 163 (2017), pp. 31-60.

Thieux, L., «Le secteur associatif en Algérie: la difficile émergence d'un espace de contestation politique», L'Année du Maghreb, vol. 5 (2009), pp. 129-144, disponible en bttps://doi.org/10.4000/anneemaghreb.545.

- Islamismo y democracia en Argelia. Francia y Estados Unidos frente al conflicto, Madrid, Ediciones del Oriente y del Mediterráneo, 2008.

- «El papel de la sociedad civil argelina en las perspectivas de cambio político en Argelia», Revista General de Derecho Público Comparado», vol. 11 (2012).

TlemçAni, R., «Algeria Under Bouteflika. Civil Strife and National Reconciliation», Carnegie Papers, 7 (2008), disponible en http://carnegieendowment.org/ files/cmec7_tlemcani_algeria_final.pdf (18 de junio de 2017).

Tubert, S., «La crisis del concepto de género», en S. Tubert (ed.), Del sexo al género. Los equívocos de un concepto, Madrid, Cátedra-Universitat de València-Instituto de la Mujer, 2003, pp. 7-38.

Villellas AriÑo, M., «La violencia sexual como arma de guerra», Quaderns de Construcció de Pau, núm. 15 (2010).

VolPI, F., «Algeria versus the Arab Spring», Journal of Democracy, vol. 24, núm. 3 (2013), pp. 104-115.

Yugueros García, A. J., «La violencia contra las mujeres: conceptos y causas», Baratalia. Revista Castellano-Manchega de Ciencias Sociales, vol. 18 (2014), pp. 147-159, disponible en bttps://doi.org/10.20932/barataria.v0i18.49.

Zerrouki, H., «L'Álgérie après la Charte pour la Paix et la Réconciliation Nationale», Recherches Internationales, vol. 75, núm. 1 (2006), pp. 25-40. 


\section{Informes y declaraciones}

Amnesty International, Algérie. Des reformes globales sont necessaires por mettre un terme à la violence sexuelle et à la violence liée au genre contre les femmes et les jeunes filles, London, Amnesty International, 2014.

Declaración Final y la Plataforma de Acción de la IV Conferencia Mundial sobre las Mujeres, Beijing, 1995, disponible en http://www.un.org/womenwatch/daw/ beijing/pdf/BDPfA\%20S.pdf (consultado el 18 de mayo de 2017).

Declaración sobre la Eliminación de la Violencia contra la Mujer (DEVM), Asamblea General de las Naciones Unidas, 20 de diciembre de 1993, disponible en http://www.ohchr.org/SP/ProfessionalInterest/Pages/ViolenceAgainstWomen. aspx (consultado el 18 de mayo de 2017).

Emakunde, Instituto Vasco de la Mujer, Violencia contra las mujeres, marzo de 2009.

Human Rights Watch, Your Destiny is to Stay with Him: State Response to Domestic Violence in Algeria, disponible en https://www.hrw.org/report/2017/04/23/ your-destiny-stay-bim/state-response-domestic-violence-algeria (consultado el 11de junio de 2017).

Instituto Nacional de Estadística, Estadística de Violencia Doméstica y Violencia de Género, 2015, disponible en http://www.ine.es/prensa/np972.pdf (consultado el 19 de mayo de 2017).

International Women's Rights Action Watch, Algeria, Initial report dated 1 September 1998, disponible en bttp://hrlibrary.umn.edu/iwraw/algeria.btm (consultado el 9 de junio de 2017).

Ministerio de Sanidad, Asuntos Sociales e Igualdad, «Violencia de género», Boletín Estadístico Anual, 2015, disponible en bttp://www.violenciagenero. msssi.gob.es/violenciaEnCifras/boletines/boletinAnual/docs/B_E_Anual_2015. $p d f$ (consultado el 11 de junio de 2017).

Protección de las mujeres contra la violencia, Recomendación rec. (2002) 5 adoptada por el Comité de Ministros del Consejo de Europa el 30 de abril de 2002 y Memorándum explicativo, Apéndice a la Recomendación rec. (2002), disponible en http://www.violenciagenero.msssi.gob.es/va/marcoInternacional/ambitoInternacional/ConsejoEuropa/Normativaldocs/Rec_2002_5_Spanish.pdf (consultado el 19 de mayo de 2017).

Réseau National des Centres d’ÉCoute sur les Violences contre les Femmes, Les violences contre les femmes en Algérie. Deuxièmes résultats, Argel, 2010, disponible en http://www.genreenaction.net/IMG/pdf/balsam2010.pdf.

Stratégie Nationale de Lutte contre la Violence à l'égard des Femmes, Argel, Ministère Délégué Chargé de la Famille et de la Condition Féminine, s.d. 


\section{ANEXO \\ TRADUCCIÓN AL ESPAÑOL DE LA LEY NÚM. 15/19, DEL 18 \\ DE RABĪ'AL-AWWAL DEL AÑO 1437, CORRESPONDIENTE AL \\ 30 DE DICIEMBRE DE 2015, MODIFICANDO Y COMPLETANDO \\ LA ORDEN NÚM. 66/156, DEL 18 DE ȘAFAR DE 1386, CORRESPONDIENTE AL 8 DE JUNIO DE 1966, QUE CONTIENE EL CÓDIGO PENAL ${ }^{61}$}

El Presidente de la República,

De acuerdo con la Constitución, especialmente sus arts. 119, 120, 122 y 126,

Conforme la Orden núm. 66/156, del 18 de șafar de 1386, correspondiente al 8 de junio de 1966, modificada y completada, que contiene el Código Penal,

Previa opinión del Consejo de Estado,

Y tras la aprobación del Parlamento,

Promulga la Ley cuyo contenido es el siguiente:

Artículo Primero. Esta Ley tiene por objetivo modificar y completar la Orden núm. 66/156, del 18 de șafar de 1386, correspondiente al 8 de junio de 1966, que contiene el Código Penal.

Artículo 2. Las disposiciones de la Orden núm. 66/156, del 18 de șafar de 1386, correspondiente al 8 de junio de 1966, antes mencionada, se completan con los arts. 266 bis y 266 bis 1 , redactados tal como sigue:

«Artículo 266 bis. Quien quiera que provoque deliberadamente heridas o golpes a su cónyuge será castigado como sigue:

1. De uno (1) a tres (3) años de cárcel si la herida o el golpe no provoca una enfermedad o una incapacidad total para trabajar de más de quince (15) días de duración.

2. De dos (2) a cinco (5) años de cárcel si provocan una incapacidad total para trabajar por un periodo de tiempo superior a quince (15) días.

3. De diez (10) a veinte (20) años de cárcel temporal si la herida o el golpe provocan la pérdida o amputación de uno de los miembros, la privación de su uso, la pérdida de la vista en ambos ojos o en uno de ellos, así como cualquier otra invalidez permanente.

${ }^{61}$ El texto completo de esta Ley puede consultarse en Al-Ŷarida al-Rasmiyya li-l$\hat{Y} u m b \bar{u}$ riyya al-Ŷaz $\bar{a}^{\prime}$ iriyya, 71 (18 rabīal-awwal 1437/30 de diciembre de 2015), pp. 3-5. Y en su versión francesa (no oficial) en Journal Officiel de la République Algérienne, 71 (30 de diciembre de 2015), pp. 3-5. La traducción al español ha sido realizada a partir del texto oficial en lengua árabe. 
4. Cadena perpetua si el golpe o la herida infringidos deliberadamente provocan la muerte, aunque fuera sin intención.

Se considerará delito tanto si el autor reside o no en el mismo domicilio con la víctima.

También se considerará delito si los actos de violencia han sido cometidos por el excónyuge y queda patente que los hechos están relacionados con la relación matrimonial anterior.

El autor no podrá beneficiarse de las circunstancias atenuantes si la víctima estuviera embarazada o discapacitada, o si el delito ha sido cometido en presencia de los hijos menores de edad, o bajo amenaza con arma.

En los casos 1 y 2, el perdón por parte de la víctima pondrá fin al procesamiento penal.

En el caso 3, cuando haya perdón por parte de la víctima, la pena será de cinco (5) a diez (10) años de cárcel».

«Artículo 266 bis 1. Será castigado con uno (1) a tres (3) años de cárcel quien cometa contra su cónyuge cualquier tipo de agresión o violencia verbal o psicológica reiterada que ponga a la víctima en una situación que atente a su dignidad o que afecte a su integridad física o psíquica.

El acto de violencia conyugal podrá ser demostrado por todos los medios.

Se considerará delito tanto si el autor reside o no en el mismo domicilio con la víctima.

También se considerará delito si los actos de violencia han sido cometidos por el excónyuge y queda patente que los hechos están relacionados con la relación matrimonial anterior.

El autor no podrá beneficiarse de las circunstancias atenuantes si la víctima estuviera embarazada o discapacitada, o si el delito ha sido cometido en presencia de los hijos menores de edad, o bajo la amenaza con arma.

El perdón por parte de la víctima pondrá fin a al procesamiento penal».

Artículo 3. Las disposiciones del art. 330 de la Orden núm. 66-156, del 18 de șafar de 1386, correspondiente al 8 de junio de 1966, antes mencionada, se modifican y quedan redactadas como sigue:

«Artículo 330 ${ }^{62}$. Será castigado con seis (6) meses a dos (2) años de cárcel y con multa de 50.000 a 200.000 DA:

1. Uno de los padres que, sin motivo serio, abandone el domicilio familiar durante más de dos (2) meses y desatienda todas sus obligaciones morales o materiales resultantes de la patria potestad o la tutela legal. El plazo de dos (2) meses

${ }^{62} \mathrm{El}$ antiguo art. 330 del Código Penal, que había sido ya modificado en el año 2006 mediante la Ley 23-06, del 20 de diciembre de 2006, decía lo siguiente en su encabezado: «Será castigado con dos (2) meses a un (1) año de cárcel y con multa de 25.000 a 100.000 DA». 
sólo podrá ser interrumpido por el regreso al domicilio familiar con el deseo de reanudar definitivamente la vida familiar ${ }^{63}$.

2. El marido que, sin motivo serio, abandone deliberadamente a su esposa durante más de dos (2) meses $^{64}$.

[El resto sin cambios $\gg_{\gg}{ }^{65}$.

Artículo 4. Las disposiciones del art. 330 de la Orden núm. 66-156, del 18 de șafar de 1386, correspondiente al 8 de junio de 1966, antes mencionada, se completan con el art. 330 bis, redactado como sigue:

«Artículo 330 bis. Será castigado con seis (6) meses a dos (2) años de cárcel quien ejerza sobre su esposa cualquier forma de coerción o intimidación para disponer de sus bienes o de sus recursos financieros.

El perdón por parte de la víctima pondrá fin a al procesamiento penal».

Artículo 5. Las disposiciones de la Orden núm. 66-156, del 18 de șafar de 1386, correspondiente al 8 de junio de 1966, antes mencionada, se completan con los arts. 333 bis 2 y 333 bis 3, redactados como sigue:

«Artículo 333 bis 2. Será castigado con dos (2) a seis (6) meses de cárcel y con multa de 20.000 a 100.000 DA, o con una de esas dos penas, quien moleste a una mujer en un lugar público con cualquier acto, palabra o gesto que ofenda su pudor.

La pena se duplicará si la víctima es una menor de menos de dieciséis años».

«Artículo 333 bis 3. A menos que el hecho constituya un delito de mayor importancia, toda agresión cometida furtivamente o con violencia, coerción o amenaza, que atente contra la intimidad sexual de la víctima, será castigada con uno (1) a tres (3) años de cárcel y con multa de 100.000 a 500.000 DA.

La pena será de dos (2) a cinco (5) años de cárcel si el autor es un familiar cercano o si la víctima es una menor de menos de dieciséis años o si la perpetración

${ }^{63}$ Anteriormente decía: «1. El padre o madre de familia que, sin motivo serio, abandone el domicilio familiar durante más de dos (2) meses y desatienda todas sus obligaciones morales o materiales resultantes de la patria potestad o la tutela legal. El plazo de dos (2) meses sólo podrá ser interrumpido por el regreso al domicilio familiar con el deseo de reanudar definitivamente la vida familiar».

${ }^{64}$ Este artículo ya había sido modificado en 2006 mediante la Ley 23-06 del 20 de diciembre de 2006. Anteriormente decía: «El marido que, sin motivo grave, abandone deliberadamente a su esposa durante más de dos (2) meses, sabiendo que está embarazada».

${ }^{65} \mathrm{El}$ art. 330 sigue del siguiente modo: «3. Uno de los padres, haya perdido o no la patria potestad, que descuide gravemente la salud, la seguridad o la moralidad de uno o varios de sus hijos mediante malos tratos, ejemplos perniciosos de embriaguez habitual o de mala conducta notoria, por falta de cuidado o por la falta de orientación necesaria. 4:- En los casos 1 y 2 de este artículo, sólo podrán adoptarse medidas de procesamiento mediante la denuncia del cónyuge abandonado. El perdón por parte de la víctima pondrán fin al procesamiento penal». 
del hecho se ha visto facilitada por la debilidad, la enfermedad, la minusvalía o la discapacidad física o mental de la víctima, o a causa del embarazo; tanto si estas circunstancias fueran aparentes como conocidas por el autor».

Artículo 6. Las disposiciones del art. 341 bis de la Orden núm. 66-156, del 18 de șafar de 1386, correspondiente al 8 de junio de 1966, antes mencionada, se modifican y quedan redactadas como sigue:

«Artículo 341 bis ${ }^{66}$. Se considerará autor de delito de acoso sexual y se castigará con uno (1) a tres (3) años de cárcel y multa de 100.000 a 300.000 DA a toda persona que abuse de la autoridad de su cargo o su profesión mediante órdenes a terceros o mediante amenazas, coerción o presión contra ellos, con el propósito de obligarles a cumplir sus deseos sexuales.

También será considerado culpable del delito previsto en el párrafo anterior y castigado con la misma pena quien acose a otros mediante cualquier acto o expresión o comportamiento que comporte un carácter o una insinuación sexual.

La pena será de dos (2) a cinco (5) años de cárcel y multa de 200.000 a 500.000 DA si el autor es un pariente cercano o si la víctima es una menor de menos de dieciséis años o si la perpetración del hecho se ha visto facilitada por la debilidad, la enfermedad, la minusvalía o la discapacidad física o mental de la víctima, o a causa del embarazo; tanto si estas circunstancias fueran aparentes como conocidas por el autor».

En caso de reincidencia la pena se duplicará».

Artículo 7. Las disposiciones del art. 368 de la Orden núm. 66-156, del 18 de șafar de 1386, correspondiente al 8 de junio de 1966, antes mencionada, se modifican y quedan redactadas como sigue:

«Artículo $368^{67}$. No serán castigados y sólo darán derecho a la indemnización civil los robos cometidos por las personas citadas a continuación:

1) Los ascendientes en perjuicio de sus hijos o demás descendientes.

2) Los descendientes en perjuicio de sus ascendientes».

Artículo 8. Las disposiciones del art. 369 de la Orden núm. 66-156, del 18 de șafar de 1386, correspondiente al 8 de junio de 1966, antes mencionada, se modifican, completan y quedan redactadas como sigue:

${ }^{66} \mathrm{El}$ anterior art. 341 bis había sido añadido mediante la Ley núm. 04-15 de 10 noviembre 2004 y decía lo siguiente: «Se considerará como autor de delito de acoso sexual, castigado con una pena de cárcel de dos (2) meses a un (1) año y una multa de cincuenta mil (50.000) a cien mil (100.000) DA, a toda persona que abuse de la autoridad su cargo o su profesión mediante órdenes a terceros o mediante amenazas, coerción o presión contra ellos, con el propósito de obligarles a cumplir sus deseos sexuales. En caso de reincidencia, la pena se duplicará».

${ }^{67}$ El anterior art. 368 añadía una tercera categoría de personas: «3) Uno de los cónyuges en perjuicio del otro cónyuge». 
«Artículo 369. Los robos cometidos entre cónyuges, parientes directos, parientes colaterales o parientes políticos hasta el cuarto grado, sólo podrán ser objeto de medidas de procesamiento penal con base en la denuncia de la persona damnificada. La retirada de la denuncia pondrá fin a estas medidas ${ }^{68}$.

[El resto sin cambios $\gg^{69}$.

Artículo 9. La presente Ley será publicada en el Boletín Oficial de la República Argelina Democrática y Popular.

Redactada en Argel el 18 de rabī al-awwal de 1437, correspondiente al 30 de diciembre de 2015.

‘Abd al-Aż̄z Būteflīqa

${ }^{68}$ Anteriormente el Código Penal no incluía a los cónyuges en este artículo y decía textualmente: «Los robos cometidos entre parientes directos, parientes colaterales o parientes políticos hasta el cuarto grado, sólo podrán ser objeto de medidas penales en base a la denuncia de la persona damnificada. La retirada de la denuncia pondrá fin a estas medidas».

${ }^{69}$ El resto del art. 369 dice lo siguiente: «A las demás personas que hayan ocultado o utilizado todos o parte de los objetos robados para su propio beneficio, se les aplicarán las penas previstas en los arts. 387 y 388 relativos a los autores del delito de encubrimiento». 